\title{
Processos de resistência de mulheres camponesas: olhares pela perspectiva decolonial
}

\author{
Renata Borges Kempf \\ Universidade Federal do Paraná, Brasil \\ renata_bk@hotmail.com \\ Josiane Carine Wedig \\ Universidade Tecnológica Federal do Paraná, Brasil \\ josianewedig@utfpr.edu.br
}

\section{Resumo:}

Este artigo aborda as dinâmicas de organização de mulheres camponesas, observando como elas, em contextos específicos, constroem ações coletivas que produzem mudanças nas relações de poder e de opressão. A análise, orientada pela perspectiva decolonial, é um estudo de caso em uma agroindústria familiar no município de Pranchita-PR. As mulheres camponesas vivenciam situações que as diferenciam das mulheres urbanas e também dos camponeses (homens). Como parte de ambas as categorias (mulher e camponês), elas sofrem duplamente os efeitos da modernidade e da colonização. Dessa maneira, o objeto do artigo se encontra na intersecção de ambas as categorias - mulher camponesa.

Palavras-CHAVE: Mulheres camponesas, Perspectiva decolonial, Agroindústria familiar.

\section{AbStract:}

This article discusses the dynamics of resistance of peasant women, observing how they, in specific contexts, construct collective actions that produce changes in the relations of power and oppression. The analysis is a case study in a family agroindustry in Pranchita-PR, oriented by the decolonial perspective. We observe that women farmers experience situations that differentiate them from urban women and also from peasants (men). As part of both categories (woman and peasant) they suffer doubly the effects of modernity and colonization. In this way the object of the article lays at the intersection of both categories - peasantwoman. KEYWORDS: Peasant women, Decolonial perspective, Family agroindustry.

\section{INTRODUÇÃO}

As formas de violência instauradas com a colonização, a partir do século XVI, sobre os diversos povos ameríndios e africanos marca a colonialidade como uma intensa relação de poder que utiliza a classificação racial dos povos. Quijano (2005) afirma que o colonialismo reconfigura as relações sociais dos lugares que foram transformados em colônias, criando formas de dominação, muitas delas vivenciadas até hoje na colonialidade do saber, do poder e do ser. Para ele, mesmo após os processos de independência dos países, mantêm-se a colonialidade estruturada por meio de classificações étnico-raciais, de gênero e de classe, que hierarquizam povos e indivíduos. Considerando essa relação, nesta comunicação discutiremos a perspectiva decolonial para entender as formas de dominação que marcam as relações entre homens e mulheres no espaço rural.

Enquanto um padrão de poder mundial, a colonialidade é caracterizada como um sistema interconectado de formas de controle, alocadas nas mãos de um grupo de instituições que são interdependentes, em que a empresa capitalista está no controle do trabalho, a família burguesa no controle do sexo, o estado-nação no controle da autoridade e o eurocentrismo no controle da intersubjetividade. Cada uma dessas formas existe em relação de interdependência com as outras e, por isso, o padrão de poder está configurado como um sistema. Esse padrão de poder mundial é o primeiro que cobre a totalidade da população do planeta (Quijano, 2005) e é denominado por Wallerstein (2001) como sistema-mundo moderno. 
Neste sentido, as formas de poder e dominação que afetam as mulheres, tanto rurais quanto urbanas, podem ser analisadas pela interseccionalidade entre raça, classe e gênero, pois estão diretamente vinculadas ao sistema patriarcal e eurocêntrico instituído pelo colonialismo. A dominação colonial impôs formas de controle da subjetividade, da cultura e do conhecimento (Quijano, 2005) e esses papéis sociais hierárquicos perpetuam as relações de dominação que se mantêm até hoje. Essas hierarquias de gênero, raça e classe criam a divisão sexual (e racial) do trabalho (Quijano, 2005).

Lugones $(2008,2014)$ analisa a interseccionalidade de gênero, classe e raça, apontando para os processos de resistência dos grupos oprimidos. Para a autora, a resistência é a tensão entre sujeitificação (formação/ informação do sujeito) e a subjetividade ativa, aquela noção mínima de agenciamento necessária para que a relação de opressão e resistência seja ativa, sem apelação ao sentido de agenciamento máximo do sujeito moderno. No caso analisado, propomos utilizar a potência do conceito de interseccionalidade para lançarmos um olhar sobre as mulheres camponesas. Os diversos dualismos que constituíram o modo de classificação do mundo a partir da colonialidade (natureza e cultura, brancos e não brancos etc.) afetam as relações sexuais de dominação. Lugones (2014) traz ao centro essa discussão a fim de compreender o modo como as mulheres foram vítimas da colonialidade do poder e do gênero, principalmente as não brancas. A interseccionalidade pode, desse modo, ser caracterizada como uma sobreposição de vulnerabilidades. No presente artigo atribuímos um especial destaque à sobreposição do modo de vida camponês à questão de gênero.

Levar em conta a interseccionalidade entre mulher e camponesa é necessário porque essas duas categorias quando abordadas separadamente não as incluem. As mulheres camponesas apresentam peculiaridades em relação às urbanas e também quanto aos homens camponeses. A literatura sobre gênero e agricultura familiar ${ }^{1}$ , quando trata dessas mulheres, geralmente tem seu enfoque nas relações de poder, nas quais elas se encontram no âmbito doméstico e no da reprodução. A perspectiva decolonial sobre o gênero nos permite olhar para essas mulheres por um ângulo que considera as consequências da modernidade (e das instituiçóes) sobre seus corpos e modos de vida. As camponesas interlocutoras da nossa pesquisa estão marcadas por questões de gênero e classe, além de estarem relacionadas ao meio rural, que, em oposição ao urbano, foi considerado como lugar de "atraso". Nesse sentido, a partir da perspectiva decolonial buscamos compreender os processos de resistência das mulheres camponesas, que se dão, na maioria das vezes, de modo sutil, o que faz com que passem despercebidos. Porém, eles podem ser compreendidos pela subjetividade ativa, que implica o processo de resistência que não procura mudar completamente o sistema de dominação, mas ao mesmo tempo encontra alternativas à dominação imposta por ele (Lugones, 2008).

As discussões que se seguem tomam como estudo de caso a Agroindústria Familiar Rural (AGF), localizada no município de Pranchita, estado do Paraná/Brasil, que pertence a um grupo de sete mulheres que há mais de 14 anos trabalham juntas, realizando todas as etapas de produção e comercialização de seus produtos. A AGF é composta unicamente por mulheres, o que nos possibilita um locus privilegiado de observação da emancipação financeira e da construção de autonomia social e política. Além disso, podemos observar as relações que essas mulheres estabelecem no espaço público de socialização, comercialização, troca e participação em organizações camponesas diversas, como sindicatos dos trabalhadores rurais, cooperativas de agricultura familiar etc.

Este trabalho ${ }^{2}$ buscou analisar os efeitos - na vida familiar e comunitária - do protagonismo de mulheres camponesas em uma agroindústria familiar rural, no qual foi possível perceber as diversas estratégias de resistência adotadas por elas, e como essas são importantes para a construção da autonomia e da reprodução social da agricultura familiar. A pesquisa de campo foi realizada entre outubro de 2015 e dezembro de 2016. Os procedimentos metodológicos pautaram-se no método qualitativo, através da realização de entrevista de trajetória e de sucessão familiar bem como de observação participante, registradas sistematicamente em diário de campo. 
O artigo se organiza em quatro partes, além dessa introdução apresentamos uma revisão bibliográfica, uma análise dos processos de resistências das mulheres camponesas e uma historicização da AGF São Roque, seu modo de funcionamento e as alterações provocadas por ela na vida dessas mulheres e de suas famílias.

\section{Perspectiva decolonial sobre as desigualdades de gênero}

As relações sociais que se configuram no processo de colonização são caracterizadas como relações de dominação, em que as identidades foram forjadas e associadas a hierarquias, lugares e papéis sociais ligadas ao padrão que se impunha. $\mathrm{O}$ advento da modernidade na Europa estabelece o dualismo entre natureza e sociedade (Latour, 1994), em que a primeira torna-se objeto ou "recurso" que deve servir ao homem, associada a uma classificação evolucionista que separa esses dois polos. Alguns povos são, então, classificados como mais próximos da natureza, considerados "selvagens" ou "primitivos", em oposição aos ocidentais europeus, definidos como "modernos" e "civilizados". Esse padrão de poder foi constituído através das classificações raciais, sexuais e de classe.

O colonialismo teve também intensa influência nas relações de gênero por meio da imposição da organização patriarcal e heterossexual. No caso das mulheres, em especial as classificadas como "raças inferiores", seus corpos foram estereotipados e "quanto mais inferiores fossem suas raças, mais perto da natureza eram objetificadas" (Quijano, 2015, p. 118). Lugones (2008) procura compreender a intersecção de raça, classe, gênero e sexualidade, investigando especialmente a violência sofrida pelas mulheres "de cor"; as não brancas, aquelas que foram vítimas da colonialidade do poder e do gênero. Para a autora, "o homem europeu, burguês, colonial moderno, tornou-se um sujeito/agente apto a decidir, para a vida pública e o governo, um ser de civilização, heterossexual, cristão, um ser de mente e razão", ao passo que a mulher europeia burguesa "não era entendida como seu complemento, mas como alguém que reproduzia raça e capital por meio de sua pureza sexual, sua passividade, e por estar atada ao lar a serviço do homem branco europeu burguês" (Lugones, 2014, p. 936).

A classificação racial foi estabelecida como instrumento de hierarquização e naturalização da exploração de certos indivíduos (Quijano, 2005). Da mesma forma, as classificações sexuais criaram distinções que recaíram, especialmente, sobre as mulheres dos países colonizados (e mais intensivamente sobre as não brancas), categorizadas como "inferiores" tanto nas suas formas de existência quanto nas suas formas de saber. A divisão do trabalho é uma consequência dessa hierarquização, quando cada grupo passou a ser considerado por meio de capacidades e direitos diferenciados, constituindo a divisão racial e sexual do trabalho (Quijano, 2005; Lugones, 2008).

A divisão sexual do trabalho é justificada pelo sistema dualista e hierárquico da modernidade, no qual as mulheres ficaram condicionadas ao espaço doméstico e privado, enquanto que aos homens foi atribuído o espaço público das relações políticas e econômicas institucionalizadas. Como salienta Wallerstein (2001), o sistema-mundo moderno criou uma divisão entre trabalho produtivo e reprodutivo, sendo que o primeiro é aquele pelo qual se recebe remuneração (salário), realizado fora da unidade domiciliar e efetuado pelo homem/pai/adulto. Já o trabalho reprodutivo (ou improdutivo) constitui a atividade de "subsistência", dentro da unidade domiciliar, realizado pela mulher/mãe/adulta. Essa divisão produziu uma desvalorização financeira e social do trabalho das mulheres e um sexismo institucionalizado.

No meio rural, entre os camponeses, ainda que as relações de trabalho não sejam assalariadas, essa realidade é perceptível. Um exemplo disso é o fato de os homens comercializarem os produtos mesmo quando esses foram produzidos pelas mulheres, algo muito comum em famílias rurais. Tal fato ocorre porque o espaço público é considerado masculino, no qual o "chefe da família" é encarado como o responsável pela realização das atividades externas à unidade de produção, encarregado das relações econômicas e políticas, como as tratativas com os bancos, as cooperativas, os sindicatos, os técnicos e os órgãos de extensão rural, por exemplo. 
Frente à colonialidade do poder, principalmente no que concerne ao gênero, produziu-se uma série de formas de resistências e de lutas por aqueles que foram submetidos aos processos de opressão. $\mathrm{O}$ feminismo pode ser considerado como uma dessas lutas, porém apresenta aspectos limitantes na consideração das pautas das mulheres não brancas, não ocidentais, não burguesas. $\mathrm{O}$ feminismo atual se mostra, em grande medida, como descendente da luta pelas demandas da mulher branca, europeia e burguesa, em relação às desigualdades com relação aos homens. Assim, a luta pela emancipação da mulher europeia é a base do feminismo eurocêntrico exportado para a colônia e ainda em voga hoje em dia. Nesse sentido, Lugones (2008, p. 94) faz uma crítica ao movimento feminista, em razão da referência hegemônica ter sido a "libertação feminina", na qual "mulheres brancas se ocuparam de teorizar o sentido branco de ser mulher, como se todas as mulheres fossem brancas”, não havendo, dessa forma, uma preocupação mais profunda com as demais mulheres: negras, indígenas, lésbicas ou camponesas, por exemplo.

Segundo Segato (2012), o feminismo eurocêntrico tem afirmado que a dominação patriarcal é universal, sem maiores diferenças, justificando a possibilidade de transmitir às mulheres não brancas dos continentes colonizados os avanços da modernidade em termos de direitos. Esse ideário passou a "sustentar" a intervenção civilizadora/colonial e modernizadora que muitas vezes tem marcado a perspectiva desse feminismo, encobrindo as consequências dessa forma de poder sobre as relações de gênero. No entanto, o que aproxima as mulheres em termos de luta contra a opressão de gênero não é um essencialismo biológico, mas, sim, a noção sociológica da opressão (Mohanty, 2008), já que cada uma sofre uma opressão diferente e por motivos diferentes, mas sempre pelo mesmo sistema.

Apesar da dificuldade da construção de um pensamento feminista não hegemônico (Masson, 2011), esse se faz necessário para que se possa compreender as demandas e estratégias dos grupos periféricos. No caso das mulheres camponesas, suas demandas são diferenciadas das mulheres urbanas - elas, por exemplo, não reivindicam o trabalho assalariado, pois para elas é importante a valorização do trabalho que vem sendo exercido na terra, o qual é invisibilizado e classificado, em geral, como "ajuda" ou como trabalho "leve", em contraposição ao "pesado", exercido pelos homens, independente da quantidade de força ou tempo de trabalho demandado para a atividade (Paulilo, 1987). A desvalorização do trabalho realizado pelas mulheres perpassa também as principais instituições da sociedade (Paulilo, 2004), como o estado, em termos de políticas públicas; os bancos, no acesso ao crédito; a participação nas cooperativas, entre outras.

Além disso, na medida em que a perspectiva da modernidade/eurocêntrica avança sobre territórios e povos impõe-se a narrativa predominante do desenvolvimento, que classifica o meio rural como o lugar do "atraso" e o espaço urbano industrial como "moderno" e locus privilegiado de mudança social. Há, nessa classificação, uma concepção evolucionista que coloca campo e cidade em um crescente civilizador, sendo a sociedade urbano-industrial uma meta a ser alcançada (Paulilo, 2004). Logo, os camponeses foram classificados como aqueles que não conseguem construir suas próprias formas de protagonismo social e político e, por isso, estariam fadados ao desaparecimento. Para Bordalo (2016, p. 5), o desconhecimento sobre as ações dos camponeses no meio rural é fruto de uma matriz intelectual que pensa a "modernidade a partir do urbano e do avanço industrial seja pelos interesses capitalistas seja pelos que pensam os processos de resistência a partir de um modelo onde o operário é protagonista”.

O processo de resistência contra a violência da dominação colonial cria um “locus fraturado", marcado "pela presença que resiste, a subjetividade ativa dos/as colonizados/as contra a invasão colonial de si próprios/as na comunidade desde o habitar-se a si mesmos/as" (Lugones, 2014, p. 943). "Locus fraturado" e "subjetividade ativa" se mostram adequados para descrever os processos de resistência das mulheres camponesas, cuja opressão extrapola o âmbito da família e se inscreve em espaços institucionais, sociais, econômicos e políticos mais amplos. Permite-nos também que as percebamos por seus processos cotidianos de resistência às formas de opressão. 


\section{EstratÉgias DE RESISTÊNCIA DAS UNIDADES CAMPONESAS E SUAS IMPLICAÇÕES PARA AS MULHERES CAMPONESAS}

Para as mulheres, o sistema capitalista pode ser considerado opressor no que concerne à divisão do trabalho, à participação política, ao controle sobre os seus corpos etc. Essa estrutura hierárquica patriarcal separa o domínio dos meios de produção dos trabalhadores, alienando seu trabalho e, além disso, fragmenta o espaço doméstico e o de produção, o que criou um padrão no qual o único esforço que merece ser chamado de trabalho produtivo é aquele que é transformado em salário. Essa situação acarretou a classificação das mulheres como responsáveis pelo ambiente doméstico, desempenhando "o papel de principal responsável pela casa e pelos filhos, o lar foi se tornando seu espaço por excelência, a ponto de a sociedade passar a só admitir seu afastamento do papel de esposa e mãe em casos de necessidade financeira" (Paulilo, 2004, p. 243). Assim, mesmo quando as mulheres trabalham fora do âmbito doméstico, isso acarreta uma dupla jornada, pois elas continuam sendo as únicas responsáveis pelas atividades domésticas, que não são consideradas trabalho.

No meio rural camponês não são observadas relações de trabalho assalariado, pois os camponeses são ao mesmo tempo trabalhadores e donos dos meios de produção. No entanto, ali também ocorre a desvalorização do trabalho das mulheres camponesas, que ficam responsáveis pelos afazeres domésticos, mesmo que trabalhem igualmente no roçado/na lavoura. Neste contexto, ocorre a indivisibilidade das rendas entre os membros da família (Chayanov, 1974) que, contudo, permanecem sob a responsabilidade do chefe de família, que, na grande maioria dos casos, é o pai/marido.

A hierarquia dos papéis de gênero é ainda muito presente dentro da agricultura familiar/camponesa, pois esse fator continua a ter grande relevância nas decisões familiares (Silva e Schneider, 2010; Kempf, 2014). As mulheres camponesas, em muitos casos, não são consideradas como possíveis sucessoras na propriedade familiar, e o status de "agricultoras" é obtido apenas através do casamento (Brumer, 2008). Desse modo, o acesso às terras por parte das mulheres é menor do que o dos homens no mundo todo, e a conquista de direitos, como em relação à herança, por exemplo, acabou não significando uma possibilidade concreta de igualdade na distribuição dessas. Paulilo (2004, p. 234) afirma que, embora existam exceções, "podemos dizer com segurança que são principalmente os filhos homens que herdam a terra”. A autora percebe ainda que a herança no meio rural está diretamente relacionada à quantidade de trabalho que os filhos e as filhas depositam na propriedade da família, sendo assim interpretada como uma remuneração pelo trabalho investido. Os filhos não herdam terras quando vão trabalhar ou estudar na cidade, por exemplo. No entanto, no caso das mulheres, independente da quantidade de trabalho dedicada à propriedade, elas raramente herdam as terras dos pais.

A agricultura, em seu formato moderno é socialmente interpretada como uma ocupação masculina, independente da quantidade de trabalho que as mulheres rurais dediquem a ela. $\mathrm{O}$ trabalho feminino é em grande parte invisível e, quando chega a ser considerado, é usualmente visto como secundário (Deere e Léon, 2003; Brumer, 2004). Existe na atividade rural uma clara divisão hierárquica, na qual os homens são os responsáveis pelas atividades produtivas e as mulheres pelas domésticas. As mulheres “ajudam” nas atividades produtivas, mas essa "ajuda" raramente é recíproca nas atividades domésticas (Brumer, 2004; Deere e Léon, 2003; Silva e Schneider, 2010). Muitas vezes, mesmo quando elas integram o processo de produção do estabelecimento, ou, então, quando são consideradas as principais responsáveis pela produção de mercadorias, as mulheres não são incumbidas da venda nem da administração dos recursos originados da produção, sendo essa uma tarefa dos homens, que fazem o contato com o exterior do domicílio (Deere e Léon, 2003; Brumer, 2004; Kempf, 2014).

Paulilo (1987) identifica situações de mulheres trabalhadoras rurais que ganham menos que a metade da diária do homem, ainda que trabalhem o mesmo número de horas. A justificativa usada é a de que o trabalho da mulher é um trabalho "leve" - independente de quão exaustivo, desgastante ou prejudicial à saúde que 
seja (Paulilo, 2004). Além disso, nas atividades em que a força física não traz maior rendimento, evita-se a presença masculina para melhor caracterizá-las como trabalho "leve", e poder assim pagar menos. A mão de obra feminina, desvalorizada, é de extrema valia para os contratantes por apresentar diversas vantagens, já que: "trabalhando bastante, não fazendo questão de registro, não dando queixa na justiça, concordam em receber menos por jornada", e sendo o sustento da casa "obrigação" do marido, a mulher "emprega-se apenas para 'ajudar em casa', ganha só 'um dinheirinho a mais”' (Paulilo, 1987, p. 3).

Através da modernização da agricultura, os camponeses passaram a ser dependentes de insumos externos: maquinários, agrotóxicos e produtos transgênicos etc., que os tornaram subordinados à indústria. Algumas das principais consequências do avanço tecnológico na agricultura apontadas por Hass (2008) dizem respeito à redução da mão de obra utilizada e à necessidade de maiores investimentos financeiros. Essas circunstâncias aliam-se ao fato de que a renda dos agricultores, quando baseada na produção de commodities, é extremamente dependente, não só das variações climáticas como das oscilações dos preços internacionais, tanto na compra de insumos quanto na venda de sua produção, deixando-os em situação de dependência de fatores dos quais não têm controle.

As unidades de produção camponesa criam resistências e alternativas frente a essas pressões externas, constituindo formas de organização da produção, das relações mercantis e de trocas através de suas relações de parentesco, vizinhança e outras alianças locais. Uma alternativa muito empregada é a da diversificação ou pluriatividade, que ocorre quando os camponeses produzem diversos cultivos ou trabalham em diferentes áreas da agricultura, da pecuária e outras. Possuir mais de uma fonte de renda rural garante uma maior segurança e melhor manutenção do estabelecimento. Schneider (2003, pp. 100-101) define a pluriatividade como a forma de organização do trabalho familiar em que os indivíduos de uma família "passam a se dedicar ao exercício de um conjunto variado de atividades econômicas e produtivas, não necessariamente ligadas à agricultura e ao cultivo da terra, e cada vez menos executadas dentro da unidade de produção".

Para Wanderley (2013, p. 52), a pluriatividade é uma estratégia familiar para assegurar a reprodução da família camponesa e "sua permanência como ponto de referência central e de convergência para todos os membros da família”, não sendo um processo gradual de abandono das atividades agrícolas, como defendem alguns pesquisadores que apontavam para a extinção do camponês devido à modernização. A autora afirma ainda que, no caso das mulheres camponesas, esse trabalho pode ter dois significados: ele pode ser uma forma de inseri-las nas rendas da família de forma individual, mesmo que esse dinheiro seja gasto em conjunto com as demais rendas, ou pode ainda gerar um distanciamento delas em relação à Unidade de Produção Familiar (UP) - provocando um processo similar ao que ocorre com os jovens rurais, quando passam a trabalhar fora da UP e têm uma profissão, deixando de ser apenas filhas e filhos de agricultores - quando deixam de ser apenas a "esposa do agricultor" (Wanderley, 2013, p. 53).

A definição de Schneider (2003) demonstra que a pluriatividade pode alterar as posições sociais na família, devido à criação de fontes de renda com caráter individual e não familiar, o que torna possível questionar o papel de provedor do homem enquanto chefe da família. Ainda que seja gasto em conjunto com as demais rendas da família, esse ganho individual pode "representar a independência (ao menos financeira) dos jovens e das mulheres, cujo trabalho na propriedade tende a ser desvalorizado e não costuma ser remunerado" (Silva, 2009a, p. 18).

As estratégias de diversificação são uma forma comum de reprodução e manutenção das famílias na agricultura familiar e têm importância para a alteração dos papeis sociais que oprimem às mulheres rurais. Geralmente, ocorrem com o objetivo de aumentar a renda familiar ou a estabilidade financeira da família, mas essas atividades podem acabar desvencilhando a mulher da esfera privada, afastando-a do âmbito doméstico e tornando-a responsável por uma atividade produtiva de grande relevância financeira para a família. Nesse sentido, as estratégias de diversificação em muitos casos podem ser consideradas como de resistência dessas mulheres, uma vez que a renda individual pode aumentar sua autonomia. 
Em uma sociedade capitalista, em que apenas o trabalho produtivo é valorizado, considerar as inúmeras atividades desenvolvidas pelas mulheres é uma forma de torná-las visíveis e mais valorizadas. Além disso, o trabalho remunerado assume uma importância significativa em uma sociedade em que quase tudo se compra e na qual o acesso a alguma forma de renda própria pode tornar as mulheres independentes dos maridos e mais participantes nas decisões que envolvem tanto o grupo doméstico como a sociedade de modo mais amplo (Paulilo e Schmidt, 2003). Os processos de resistência são constantes entre as mulheres rurais e, em muitos casos, os papeis tradicionais de gênero estão se modificando. $\mathrm{O}$ tópico a seguir trata desses processos.

\section{A construÇão da autonomia das mulheres na organizaÇão da Agroindústria Familiar Rural São RoQue}

A AGF estudada foi criada em 2001; produz massas e panificações que são comercializadas na comunidade, no município e na região. O grupo se formou através de uma proposta da prefeitura, apresentada em uma reunião com os moradores da comunidade, introduzindo a possibilidade de investimento através do Programa Paraná 12 meses, programa financiado pelo Banco Mundial para apoio financeiro de agricultores familiares, pescadores artesanais, trabalhadores rurais e comunidades indígenas (SIMEP, 2016).

Sobre estes investimentos do Banco Mundial para estes grupos, Walsh (2010) analisou como os organismos multilaterais têm criado discursos públicos de inclusão, constituindo o que ela denominou como um multiculturalismo neoliberal, que fortalece as estruturas sociais da matriz colonial, em que ocorrem tentativas de controle social dos subalternizados. Estes organismos instituem uma inclusão que reduz conflitos raciais ou de gênero, ao mesmo tempo em que incrementa a eficiência econômica da ação estatal e do mercado. Portanto, menos do que o reconhecimento da necessidade de transformação das relações sociais, esta "é uma estratégia política funcional do sistema/mundo moderno e ainda colonial ; que pretende 'incluir' aqueles anteriormente excluídos do modelo globalizado de sociedade, regido não pelas pessoas, mas pelos interesses de mercado" (WALSH, 2009, p. 20).

De acordo com as mulheres do grupo, o investimento foi recebido por diversas comunidades na mesma época, no entanto apenas elas ainda mantêm a AGF. Elas apontam como causa da continuidade os laços existentes entre o grupo antes da criação da agroindústria, a persistência, além das relações e redes de apoio que possuem, envolvendo a comunidade e outras organizações e instituições locais, como a prefeitura, o sindicato, as cooperativas, o comércio local etc. É a partir desse projeto que as mulheres agricultoras elegem uma alternativa que é proveniente do mundo externo à comunidade, mas que é ativada na interação entre elas, nas alianças que estabelecem entre si na construção de processos de maior autonomia.

No início da agroindústria, a antiga escola desativada da comunidade foi cedida como sede de instalação para as 13 mulheres interessadas em participar do projeto. $O$ grupo diminuiu ao longo dos anos, estabilizando-se nas sete atuais participantes. Durante os 14 anos de existência da fábrica ${ }^{3}$, seis mulheres abandonaram a atividade e o principal motivo apontado para a sua saída, segundo aquelas que permaneceram, foi a idade. Outro motivo foi que no terceiro ano de existência da fábrica as mulheres decidiram financiar um carro para realizar a entrega de seus produtos, e muitas delas desistiram por receio do compromisso a longo prazo e do risco assumido com as parcelas do carro.

Não há uma rotatividade das participantes na fábrica, mantém-se o mesmo grupo inicial. Sobre essa questão, Fátima, uma das integrantes, expressa: “agora não pode entrar mais gente porque aquela vez foi deixado livre para quem quisesse assumir o projeto, teve bastantes dificuldades que nós tivemos para conquistar tudo o que conquistamos, teve o carro, a garagem e agora a gente não aceita qualquer pessoa entrar aqui não".

As mulheres trabalham na fábrica de segunda a sexta-feira e afirmam continuar com a atividade agrícola nos finais de semana e nos horários "livres". Ao serem questionadas sobre sua profissão, todas responderam que são agricultoras. A dupla jornada é uma característica comum às mulheres camponesas com fontes de rendas 
diversificadas, frequentemente referidas na literatura sobre gênero e ruralidades (Brumer, 2004; Paulilo, 1987; Schneider, 2003; Carneiro, 2003).

$\mathrm{Na}$ AGF São Roque ocorre uma forma associativa de organização do trabalho que envolve o grupo e a comunidade. Ali se destacam as relações sociais de amizade, parentesco, confiança e reciprocidade. Dessa forma, a história da comunidade tem especial importância na construção desse empreendimento associativo. As mulheres camponesas diversas vezes nas conversas destacaram a importância da comunidade para a permanência da AGF:

A comunidade é bem unida (...) sempre se trabalhou junto. Quando nós abrimos aqui nós tivemos todo o apoio da comunidade, a gente tem muita ligação com a comunidade. Eles têm acesso aqui [na fábrica] se precisar de alguma coisa e nós temos acesso [a outros espaços] na comunidade. Se precisar, eles estão prontos para ajudar, não tem isso de eu sou eu e você é você. Acho que é por isso que deu certo (Ana).

Nesse sentido, as mulheres do grupo utilizam os laços sociais comunitários para manter a fábrica em funcionamento e, além disso, criam outros. Fábrica e comunidade estão interligadas. Os vínculos existentes entre as mulheres estabelecem relações de reciprocidade e ajuda mútua nas mais diversas atividades comunitárias, como as festividades, as celebrações religiosas, os espaços de participação, como o sindicato, a cooperativa, entre outros. Com a criação da fábrica, elas rompem com o encapsulamento da domesticidade (Segato, 2012), da esfera privada, e passam a utilizar também os espaços públicos que antes eram de responsabilidade apenas dos homens. Isso lhes permitiu desnaturalizar a sua invisibilidade e a de seu trabalho, que era classificado como estritamente doméstico, mesmo quando exerciam inúmeras tarefas destinadas à produção para o autoconsumo e comercialização de excedentes.

Para essas mulheres camponesas, o contato com o exterior da UP tem especial importância, pois lhes permite a participação em feiras, cursos, contatos com instituições e outras organizações etc. As saídas para comercialização não criam apenas relações sociais importantes para as mulheres e, além disso, apresentam reflexos no reconhecimento de seu trabalho dentro e fora da fábrica, tanto na economia familiar como na autoestima de cada uma delas e nos laços desenvolvidos entre si, configurando-se como importantes atores sociais na comunidade e no município.

A forma de organização do trabalho das mulheres na agroindústria apresenta certas especificidades: as horas trabalhadas são organizadas em um banco de horas, em que cada integrante anota a quantidade diariamente, e essas são somadas no final do mês para que elas possam ter uma remuneração proporcional. Considerando a remuneração média de produção da agroindústria, é possível mensurar que a renda das mulheres se mostra similar e até mesmo em alguns casos superior a dos maridos. Elas também se organizam em uma espécie de rodízio, em que são respeitadas as características e aptidões de cada uma, ao mesmo tempo em que dividem as atividades mais maçantes. Não existe uma liderança ou alguém que delegue tarefas, elas trocam de atividade e começam outra de forma sinergética. As mulheres têm livre controle da quantidade de horas trabalhadas na agroindústria e regulam essas de acordo com suas necessidades, trabalhando mais tempo em momentos de crise na produção familiar principal e menos quando a propriedade familiar tem uma boa produção.

A agroindústria rural, como estratégia de reprodução familiar, organiza-se de forma similar à produção familiar, em que a quantidade a se produzir é definida de acordo com as necessidades familiares, seguindo a descrição de Chayanov (1974). Da mesma forma que o camponês não procura aumentar suas terras a todo custo e contratar mão de obra externa, o grupo de mulheres mantém um padrão de produção nos 14 anos de existência da fábrica, trabalhando sempre de forma conjunta e associativa, sem visar a ampliação contínua da fábrica.

Para todas as mulheres da agroindústria o bem-estar da família é a motivação para a participação da atividade, e a renda obtida com a fábrica é direcionada para os gastos “da casa” em todas as situações. A renda familiar adicional, segundo Frank Ellis (2000), tem efeitos diferentes para homens e mulheres: os homens 
teriam uma tendência maior a usar o dinheiro para gastos pessoais enquanto as mulheres usariam o dinheiro para melhorar o bem-estar e a saúde da família.

As famílias não apresentaram abertamente relutância à inserção das mulheres na atividade de produção e no contato com o espaço público. Possíveis explicações para tal aceitação é o fato de a AGF estar localizada na comunidade onde moram e, dessa forma, não há um afastamento completo da unidade de produção familiar. Ao mesmo tempo, há a necessidade do dinheiro obtido com a AGF, sendo que em algumas famílias é a principal renda familiar.

Embora todas as mulheres, quando questionadas sobre a organização financeira familiar, afirmassem que não existe separação do dinheiro do casal. É possível identificar discursos em que se referem a essas rendas como "dinheiro meu" em oposição ao "dinheiro dele" - que vem da venda de produtos agrícolas, demonstrando especialmente a importância dessa forma de diversificação em específico, por fornecer à mulher uma renda além da renda familiar, ainda que essa possa ser gasta em conjunto. Ao separar o dinheiro em "meu" ou "dele", elas passam a mensurar o real valor da sua participação financeira dentro do grupo doméstico e isso é algo capaz de alterar as dinâmicas dos espaços em que residem.

O afastamento do ambiente doméstico tensiona a responsabilidade pelo trabalho, pois provoca alterações na dinâmica doméstica, no entanto, essas alterações não significam que os homens assumam, de fato, esse trabalho. Na maioria dos casos, as 8 horas diárias trabalhadas na AGF geram uma dupla jornada de trabalho para as mulheres, as quais ainda são consideradas responsáveis pelo trabalho doméstico, mesmo estando menos tempo em casa do que seus maridos. Em dois casos há uma transferência dessas atividades para as filhas adolescentes, que passam a ser encarregadas pelas lidas domésticas.

Há casos em que ocorre uma pequena inserção dos maridos nessas tarefas, especialmente através do preparo do almoço - alguns o preparam todos os dias e outros apenas nos dias de venda, quando as mulheres seguem horários de trabalho mais intensos. A assunção dessa responsabilidade pelos maridos não ocorre sem certa relutância por parte deles. Uma das mulheres, quando questionada sobre as principais mudanças familiares após a participação dela na fábrica, é interrompida pelo marido que, com certo rancor, responde: "agora eu que tenho que fazer o almoço". Ela explica que como condição para exercer essa nova função, ele exigiu que fosse instalado um fogão do lado de fora, atrás da casa, demonstrando a relutância em se apropriar da cozinha e em ser visto pelos vizinhos executando essa tarefa, julgada como feminina. Por ser um trabalho considerado doméstico e feminino, o trabalho na cozinha é tratado de maneira pejorativa quando conhecemos, por exemplo, a fala desse marido que só aceitou fazer almoço quando o fogáo foi transferido para o espaço externo.

Olhando para o espaço doméstico camponês é possível perceber que os papéis de gênero se relacionam com as concepções de "dentro" e "fora" de casa. Dessa forma, o trabalho executado "dentro de casa" é feminino e esse espaço pertence fundamentalmente à mulher, enquanto o de "fora de casa", e fora da propriedade, é de domínio masculino. Além da divisão do trabalho, a questão espacial se mostra relevante quando notamos que a produção do alimento cozido (na cozinha) é algo considerado feminino, enquanto o alimento feito fora de casa, como o abate animal e a preparação das carnes, por exemplo, é masculino (Silva, 2009b; Wedig, 2009).

Dessa forma, para a mulher torna-se especialmente importante essa saída "da cozinha" e a realização de uma atividade externa ao ambiente doméstico. Em nosso caso, mais do que uma saída da cozinha percebemos uma troca de cozinhas, transferindo o trabalho doméstico para o âmbito "produtivo". Nessa transferência, o trabalho deixa de ser "sem valor" e passa a ser uma atividade produtiva e, como tal, mais valorizada, especialmente quando se considera os rendimentos mensais mensuráveis. Ao analisarmos esses diversos tensionamentos observamos como é difícil em um ambiente com relações patriarcais intensamente arraigadas, para as mulheres camponesas tornarem-se independentes financeiramente e organizarem autonomamente as suas atividades, pois as tarefas de comercialização e o uso do espaço público de participação é normalmente definido como um lugar a ser ocupado apenas pelos homens. Nessa construção de outras relações sociais no meio rural, as mulheres camponesas precisam de grande energia e coragem para não ceder às pressões que sobre elas pendem em termos familiares e mesmo comunitários. As 
cobranças que são feitas para as mulheres ocuparem "seu lugar" no espaço doméstico ou mesmo darem conta de uma dupla ou tripla jornada de trabalho nas comunidades rurais pode ser um dos motivos de abandono das outras mulheres que já integraram a agroindústria.

Nesta estratégia de diversificação dos meios de vida, as mulheres da AGF de Pranchita conseguem uma maior autonomia financeira e social, transformando as condiçóes materiais de sua invisibilidade. Elas se afastam parcialmente do ambiente doméstico, das atividades reprodutivas e mais desvalorizadas a partir da subjetividade ativa, em que não ocorre uma transformação geral de todo o processo de opressão de gênero, mas constroem formas locais e cotidianas de resistências.

\section{CONSIDERAÇÕES FINAIS}

Nesse estudo foi possível perceber as diversas peculiaridades das estratégias de resistência adotadas pelas mulheres camponesas, de como são importantes para a ampliação de sua autonomia e, ao mesmo tempo, para garantir as estratégias de reprodução social da agricultura familiar. Buscou-se identificar as alternativas construídas pelas mulheres bem como as redes de relações que o processo edificou em sua caminhada até aqui.

O feminismo decolonial, que orientou a nossa análise, aporta uma visão das violências coloniais vividas pelas mulheres - que se diferenciam para cada um dos grupos. Essa perspectiva busca perceber as resistências que surgem nesse "locus fraturado" através da ênfase na "subjetividade ativa" das resistências cotidianas das mulheres. Entre as mulheres camponesas foi possível perceber um processo de resistência às relações patriarcais opressivas dentro de casa - que se modificam sutilmente - e também a resistência em relação aos papeis de gênero impostos a elas, o que constitui uma modificação das relações sociais naturalizadas. A atividade das mulheres na fábrica ultrapassa a dimensão da produção e do ganho econômico, pois permite também uma organização política delas, ligada a uma política do cotidiano, na qual elas constroem táticas e estratégias para a construção de uma melhor qualidade de vida para si, sua família e comunidade.

No caso estudado, o grupo utiliza-se de estratégias de diversificação dos meios de vida que objetivam melhorias no bem-estar familiar. Essas estratégias acabam tendo influência na emancipação financeira das mulheres e especialmente no estímulo à autonomia de cada uma delas. A AGF possibilitou para elas mais do que apenas uma forma de renda; foi uma mudança em suas rotinas, pois passaram a viajar para feiras, eventos e cursos, a ter contatos maiores com outras comunidades, consequência de suas posições profissionais fora do núcleo familiar; a estabelecerem redes de contato comercial em sua cidade e nas cidades vizinhas, a valorizar o "saber fazer" relacionado à produção, às vendas e à organização financeira da AGF, que cada uma delas possui. Tudo isso influencia diretamente a autonomia dessas mulheres, através do protagonismo propiciado pela diversificação dos seus meios de vida. Diversificar, dessa forma, é uma maneira de resistência, sem confronto direto, e que pode ser caracterizada como a subjetividade ativa dessas mulheres que resistem ao sistema econômico que as desvaloriza, às famílias que as invisibilizam e às instituições que corroboram com essa opressão, criando resistências no locus fraturado em que se encontram.

O fato de ser uma organização exclusivamente gerida por mulheres as coloca em diferentes funções e as leva a assumir papéis que comumente seriam considerados masculinos. Esse grupo de mulheres camponesas - que não só têm ganhos econômicos equivalentes aos dos maridos como também têm carro próprio e acesso aos mercados urbanos - frequenta cursos em diversas cidades, acessa crédito e políticas públicas, administra as contas da agroindústria e demonstra que os papeis de gênero podem e devem ser modificados, e que essas mudanças estão ocorrendo e precisam ser reconhecidas como tais.

\section{REFERÊNCIAS}

Bordalo, C. A. (2016). Desenvolvimento, Campesinato e Feminismo na América Latina: uma análise das formas de representação política no campo brasileiro. 40 Encontro Anual da ANPOCS, Caxambu-MG. 
Brumer, A. (2004). Gênero e agricultura: a situação da mulher na agricultura do Rio Grande do Sul. Estudos Feministas, 12(1), 205-227.

Brumer, A. (2008). Gênero e reprodução social na agricultura familiar, Revista NERA, 11(12), 6-17.

Carneiro, S. (2003). Enegrecer o feminismo: a situação da mulher negra na América Latina a partir de uma perspectiva de gênero. Em Ashoka Empreendimentos Sociais e Takano Cidadania (Orgs.), Racismos contemporâneos (pp. 49-58). Rio de Janeiro: Takano Editora.

Chayanov, A. V. (1974). La organización de la unidad económica campesina. Argentina: Nueva Visión.

Deere, C. D., y Léon, M. (2003). Diferenças de gênero em relação a bens: a propriedade fundiária na América Latina. Revista Sociologias, 5(10), 100-153.

Ellis, F. (2000). Rural livelihoods and diversity in developing countries. Oxford: Oxford University Press.

Haas, J. M. (2008). Diversificação de produção no meio rural como estratégia de sobrevivência: um estudo de caso da região Noroeste do Rio Grande do Sul. IV Encontro Nacional da ANPPS, Brasília.

Kempf, R. B. (2014). Análise de gênero e autonomia financeira na agricultura familiar através do programa "gênero e geração" (Dissertação de mestrado), Universidade Estadual do Centro-Oeste, Faculdade de Ciências Econômicas, Guarapuava, Brasil.

Latour, B. (1994). Jamais fomos modernos. Rio de Janeiro: Editora 34.

Lugones, M. (2008). Coloniality and gender. Tabula rasa, (9), 73-102.

Lugones, M. (2014). Rumo a um feminismo descolonial. Estudos feministas, 22(3), 935-952.

Masson, S. (2011). Sexo/género, clase, raza: feminismo descolonial frente a la globalización: Reflexiones inspiradas a partir de la lucha de las mujeres indígenas en Chiapas. Andamios, 8(17), 145-177.

Paulilo, M. I. (1987). O peso do trabalho leve. Revista Ciência Hoje. 5(28), 64-70.

Paulilo, M. I. (2004). Trabalho familiar: uma categoria esquecida de análise. Revista Estudos Feministas. 12(1) 229-252.

Paulilo, M. I., e Schmidt, W. (2003). Agricultura e espaço rural em Santa Catarina. Florianópolis: Editora UFSC.

Quijano, A. (2005). Colonialidad del poder, eurocentrismo y América Latina. (2000). Em E. Lander (Org.), La colonialidad del saber: eurocentrismo y ciencias sociales. Perspectivas Latinoamericanas (pp. 201-246). Buenos Aires: CLACSO, Consejo Latinoamericano de Ciencias Sociales.

Quijano, A. (2015). Colonialidad del poder y clasificación social. Contextualizaciones Latinoamericanas, (5). [pp. $342-386]$

Schneider, S. (2003). A pluriatividade na agricultura familiar. Porto Alegre: Editora da UFRGS.

Segato, R. L. (2012). Gênero e colonialidade: em busca de chaves de leitura e de um vocabulário estratégico descolonial. E-cadernos ces, (18), 106-131.

Silva, C. B. (2009a). Pluriatividade e relaçôes de gênero na agricultura familiar do Rio Grande do Sul (Dissertação de Mestrado), Universidade Federal do Rio Grande só Sul, Programa de Pós-Graduação em Sociologia, Porto Alegre, Brasil.

Silva, M. A. D. (2009b). Cozinha: espaço de relações sociais. Revista Iluminuras- [n.23, v. 10, s/p] Publicação Eletrônica do Banco de Imagens e Efeitos Visuais.

Silva, C. B. D. C., e Schneider, S. (2010). Gênero, trabalho rural e pluriatividade. Em P. Scott, R. Cordeiro e M. Menezes (Org.), Gênero e geração em contextos rurais (pp. 183-208). Florianópolis: Ed. Mulheres.

Simep. Paraná 12 meses, Disponível em: http://www.simep.seab.pr.gov.br/pr12meses/, Acesso em: 20/12/2016

Mohanty, C. (2008). Bajo los ojos de Occidente. Academia Feminista y discurso colonial. Em L. Suarez e R. Hernandez [eds], Descolonizando el feminismo: teorias y prácticas desde los márgenes (pp. 117-163). Madrid: Editora Cátedra.

Wallerstein, I. (2001). Capitalismo histórico e civilização capitalista. Rio de Janeiro: Editora Contraponto.

Walsh, C. (2009). Interculturalidade Crítica e Pedagogia Decolonial: in-surgir, re-existir y re-vivir. Em V. M. Candau (Org.), Educação Intercultural na América Latina: entre concepções, tensões e propostas (pp. 12-43).Rio de Janeiro: 7 Letras. 
Wanderley, M. N. (2003). Agricultura familiar e campesinato: rupturas e continuidade. Estudos sociedade eagricultura, $21,42-61$.

Wedig, J. C. (2009). Agricultoras e agricultores à mesa: um estudo sobre campesinato e gênero a partir da antropologia da alimentação (Dissertação de Mestrado), Universidade Federal do Rio Grande só Sul, Programa de PósGraduação em Desenvolvimento Rural, Porto Alegre, Brasil.

\section{Notas}

1 No decorrer do texto, poderão ser encontrados ambos os termos agricultura familiar e campesinato, com o objetivo de descrever o grupo pesquisado. Para Wanderley (1996; 2004), o campesinato é uma forma de agricultura abrangida pelo conceito de agricultura familiar. Sendo assim, o conceito utilizado neste artigo considera a agricultura familiar como um conceito genérico que abrange diversas formas de agricultura e o campesinato está incluso nessa categoria.

2 Essa pesquisa é resultado de uma investigação para a dissertação do mestrado em Desenvolvimento Regional da Universidade Tecnológica Federal do Paraná (UTFPR). A pesquisa foi financiada com bolsa da Coordenação de Aperfeiçoamento de Pessoal de Nível Superior (CAPES) e apoio da Fundação Araucária, agência de financiamento de pesquisa do estado do Paraná.

3 Termo utilizado pelo grupo para se referir à AGF. 